\title{
Determinants of variations in initial treatment strategies for stable ischemic heart disease
}

\author{
Maria C. Bennell MPH, Feng Qiu MSc, Kori J. Kingsbury MSN, Peter C. Austin PhD, \\ Harindra C. Wijeysundera MD
}

CMAJ Podcasts: author interview at soundcloud.com/cmajpodcasts/bennell-ischemic

\begin{abstract}
- Abstract
Background: The ratio of revascularization to medical therapy (referred to herein as the revascularization ratio) for the initial treatment of stable ischemic heart disease varies considerably across hospitals. We conducted a comprehensive study to identify patient, physician and hospital factors associated with variations in the revascularization ratio across 18 cardiac centres in the province of Ontario. We also explored whether clinical outcomes differed between hospitals with high, medium and low ratios.

Methods: We identified all patients in Ontario who had stable ischemic heart disease documented by index angiography performed between Oct. 1, 2008, and Sept. 30, 2011, at any of the 18 cardiac centres in the province. We classified patients by initial treatment strategy (medical therapy or revascularization). Hospitals were classified into equal tertiles based on their revascularization ratio. The primary outcome was all-cause mortality. Patient followup was until Dec. 31, 2012. Hierarchical logistic regression models identified predictors of revascularization. Multivariable Cox proportional
\end{abstract}

hazards models, with a time-varying covariate for actual treatment received, were used to evaluate the impact of the revascularization ratio on clinical outcomes.

Results: Variation in revascularization ratios was twofold across the hospitals. Patient factors accounted for $67.4 \%$ of the variation in revascularization ratios. Physician and hospital factors were not significantly associated with the variation. Significant patient-level predictors of revascularization were history of smoking, multivesse disease, high-risk findings on noninvasive stress testing and more severe symptoms of angina (v. no symptoms). Treatment at hospitals with a high revascularization ratio was associated with increased mortality compared with treatment at hospitals with a low ratio (hazard ratio 1.12 $95 \%$ confidence interval 1.03-1.21).

Interpretation: Most of the variation in revascularization ratios across hospitals was warranted, in that it was driven by patient factors. Nonetheless, the variation was associated with potentially important differences in mortality.
$\mathrm{S}$ table ischemic heart disease is a common manifestation of cardiovascular disease, the leading cause of death in the world..$^{1,2}$ The treatment strategies for stable ischemic heart disease include medical therapy alone or in combination with revascularization by percutaneous coronary intervention (PCI) or coronary artery bypass grafting $(\mathrm{CABG})$.

A tremendous amount of research has examined the best initial treatment strategy for stable ischemic heart disease. ${ }^{3-5}$ Randomized controlled trials have not shown a difference in major adverse events between optimal medical therapy and revascularization. ${ }^{6}$ Some argue that revascularization should be reserved only for symptom relief. ${ }^{5,78}$ Criteria for the appropriate use of revascularization have been developed to aid in clinical decision-making; however, a substantial proportion of revascularization procedures for stable ischemic heart disease are performed under clinical circumstances deemed as "uncertain." ${ }^{\prime, 10}$ Reflecting this uncertainty, there is wide regional variation in the rate of coronary revascularization, ${ }^{11-13}$ which suggests different thresholds for invasive therapy for stable ischemic heart disease.

Studies have predominantly examined the determinants of variations in the type of revascularization modality used. ${ }^{13,14}$ There is a paucity of data exploring the determinants of variations in the earlier decision to treat with medical therapy alone or with revascularization. A study published nearly a decade ago did not examine outcomes. ${ }^{7}$ Accordingly, our primary research objective was to determine whether the variations in initial
Competing interests: None declared.

This article has been peer reviewed.

Correspondence to: Harindra Wijeysundera, harindra.wijeysundera@ sunnybrook.ca

Accepted: Apr. 14, 2015 Online: May 19, 2015

CMAJ 2015. DOI:10.1503 /cmaj.141372 
Table 1 (part 1 of 2): Baseline patient, physician and hospital characteristics by initial treatment strategy for stable ischemic heart disease

\begin{tabular}{|c|c|c|c|c|}
\hline \multirow[b]{2}{*}{ Characteristic } & \multicolumn{3}{|c|}{ Initial treatment strategy; \% of patients* } & \multirow[b]{2}{*}{$p$ valuet } \\
\hline & $\begin{array}{c}\text { Total } \\
n=39131\end{array}$ & $\begin{array}{l}\text { Medical therapy } \\
n=15139\end{array}$ & $\begin{array}{c}\text { Revascularization } \\
n=23992\end{array}$ & \\
\hline \multicolumn{5}{|l|}{ Patient } \\
\hline Age, yr, mean $\pm S D$ & $66.0 \pm 10.3$ & $67.0 \pm 10.2$ & $65.3 \pm 10.3$ & $<0.001$ \\
\hline Male sex & 75.3 & 74.3 & 75.9 & $<0.001$ \\
\hline Rural residence & 14.5 & 14.4 & 14.5 & 0.7 \\
\hline Income quintile & & & & $<0.001$ \\
\hline 1 (lowest) & 18.6 & 19.6 & 17.9 & \\
\hline 2 & 20.4 & 20.4 & 20.4 & \\
\hline 3 & 20.2 & 20.3 & 20.2 & \\
\hline 4 & 20.7 & 20.2 & 21.0 & \\
\hline 5 (highest) & 20.1 & 19.4 & 20.5 & \\
\hline \multicolumn{5}{|l|}{ Medical comorbidity } \\
\hline Peripheral vascular disease & 9.4 & 11.5 & 8.1 & $<0.001$ \\
\hline Prior MI & 28.1 & 35.8 & 23.3 & $<0.001$ \\
\hline COPD & 6.9 & 8.6 & 5.8 & $<0.001$ \\
\hline Charlson comorbidity score, mean \pm SD & $0.9 \pm 1.3$ & $1.1 \pm 1.5$ & $0.8 \pm 1.2$ & $<0.001$ \\
\hline \multicolumn{5}{|l|}{ Cardiac risk factors } \\
\hline Diabetes & 44.0 & 48.0 & 41.4 & $<0.001$ \\
\hline Hypertension & 86.7 & 89.5 & 84.9 & $<0.001$ \\
\hline Hyperlipidemia & 80.8 & 83.0 & 79.5 & $<0.001$ \\
\hline History of smoking & 31.6 & 33.2 & 30.5 & $<0.001$ \\
\hline \multicolumn{5}{|l|}{ Cardiac status/testing } \\
\hline \multicolumn{5}{|l|}{ Native stenosis $¥$} \\
\hline Left main coronary artery & 13.0 & 10.8 & 14.4 & $<0.001$ \\
\hline Proxmal left anterior descending coronary artery & 33.2 & 28.7 & 36.0 & $<0.001$ \\
\hline $\begin{array}{l}\text { Mid or distal left anterior descending } \\
\text { coronary artery }\end{array}$ & 49.6 & 47.5 & 51.0 & $<0.001$ \\
\hline Circumflex artery & 51.5 & 50.9 & 51.9 & 0.07 \\
\hline Right coronary artery & 60.8 & 60.5 & 60.9 & 0.4 \\
\hline Prior CABG & & & & $<0.001$ \\
\hline Yes & 18.0 & 30.1 & 10.4 & \\
\hline No & 81.9 & 69.9 & 89.5 & \\
\hline Unknown & 0.1 & 0.1 & 0.1 & \\
\hline Vessel disease & & & & $<0.001$ \\
\hline 1 vessel & 38.9 & 42.0 & 36.9 & \\
\hline 2 vessels & 25.8 & 24.0 & 27.0 & \\
\hline 3 vessels & 34.5 & 32.5 & 35.8 & \\
\hline Missing data & 0.8 & 1.5 & 0.3 & \\
\hline Left ventricular function & & & & $<0.001$ \\
\hline$\leq 34 \%$ & 5.4 & 8.4 & 3.5 & \\
\hline $35 \%-49 \%$ & 12.9 & 16.0 & 11.0 & \\
\hline$\geq 50 \%$ & 48.6 & 46.5 & 50.0 & \\
\hline Not done & 33.0 & 29.1 & 35.5 & \\
\hline
\end{tabular}


Table 1 (part 2 of 2): Baseline patient, physician and hospital characteristics by initial treatment strategy for stable ischemic heart disease

\begin{tabular}{|c|c|c|c|c|}
\hline \multirow[b]{2}{*}{ Characteristic } & \multicolumn{3}{|c|}{ Initial treatment strategy; \% of patients* } & \multirow[b]{2}{*}{$p$ valuet } \\
\hline & $\begin{array}{c}\text { Total } \\
n=39131\end{array}$ & $\begin{array}{c}\text { Medical therapy } \\
n=15139\end{array}$ & $\begin{array}{c}\text { Revascularization } \\
n=23992\end{array}$ & \\
\hline \multicolumn{2}{|l|}{ Exercise ECG risk } & & & $<0.001$ \\
\hline High risk & 27.7 & 21.3 & 31.7 & \\
\hline Low risk & 22.4 & 22.9 & 22.2 & \\
\hline Uninterpretable & 4.9 & 4.8 & 4.9 & \\
\hline Not done & 45.0 & 51.1 & 41.2 & \\
\hline \multicolumn{2}{|l|}{ Functional imaging risk } & & & $<0.001$ \\
\hline High risk & 32.0 & 31.2 & 32.6 & \\
\hline Low risk & 23.0 & 25.1 & 21.7 & \\
\hline Not done & 44.9 & 43.7 & 45.7 & \\
\hline \multicolumn{2}{|l|}{ CCS class } & & & $<0.001$ \\
\hline 0 & 16.5 & 22.0 & 13.0 & \\
\hline 1 & 14.0 & 15.9 & 12.8 & \\
\hline 2 & 38.3 & 35.5 & 40.0 & \\
\hline 3 & 28.5 & 24.2 & 31.1 & \\
\hline 4 & 2.8 & 2.4 & 3.0 & \\
\hline \multicolumn{5}{|l|}{ Physician§ } \\
\hline Age, yr, mean \pm SD & $48.3 \pm 9.1$ & $48.8 \pm 9.1$ & $47.9 \pm 9.0$ & $<0.001$ \\
\hline \multicolumn{2}{|l|}{ Sex } & & & 0.2 \\
\hline Female & 3.7 & 3.9 & 3.6 & \\
\hline Male & 94.7 & 94.5 & 94.9 & \\
\hline Unknown & 1.5 & 1.6 & 1.5 & \\
\hline Years since graduation, mean \pm SD & $23.4 \pm 9.3$ & $23.9 \pm 9.3$ & $23.1 \pm 9.3$ & $<0.001$ \\
\hline Total consultations billed per year, mean \pm SD & $856.5 \pm 424.7$ & $863.0 \pm 424.5$ & $852.4 \pm 424.8$ & 0.02 \\
\hline Total visits billed per year, mean \pm SD & $2613.9 \pm 1730.7$ & $2707.5 \pm 1773.6$ & $2555.0 \pm 1700.5$ & $<0.001$ \\
\hline \multicolumn{5}{|l|}{ Hospital } \\
\hline Annual catheterization volume, mean \pm SD & $4092.3 \pm 1696.4$ & $4031.3 \pm 1684.3$ & $4130.9 \pm 1702.9$ & $<0.001$ \\
\hline \multicolumn{2}{|l|}{ Hospital type } & & & $<0.001$ \\
\hline Catheterization only & 13.2 & 13.6 & 13.0 & \\
\hline $\mathrm{PCl}$ and cathetherization only & 6.1 & 7.2 & 5.4 & \\
\hline $\mathrm{CABG}, \mathrm{PCl}$ and catheterization & 80.8 & 79.3 & 81.7 & \\
\hline \multicolumn{5}{|c|}{$\begin{array}{l}\text { Note: } C A B G=\text { coronary artery bypass grafting, } C C S=\text { Canadian Cardiovascular Society, } C O P D=\text { chronic obstructive pulmonary disease, ECG = electrocardiogram, } \\
\text { MI = myocardial infarction, } \mathrm{PCI}=\text { percutaneous coronary intervention, } \mathrm{SD}=\text { standard deviation. } \\
\text { *Unless stated otherwise. } \\
\text { tWe assessed differences in baseline characteristics between initial treatment strategy and hospital revascularization ratio strata using the } \chi^{2} \text { test for categorical } \\
\text { variables and analysis of variance for continuous variables. } \\
\text { tSignificant stenosis } \geq 70 \% \text { ( } \geq 50 \% \text { in left main coronary artery). } \\
\text { \$Procedural physician. }\end{array}$} \\
\hline
\end{tabular}

treatment strategies for stable ischemic heart disease are warranted. We conducted a comprehensive population-based study to identify patient, physician and hospital factors associated with variations in treatment strategies within 90 days after angiography. We also explored whether clinical outcomes differed between hospitals with high, medium and low ratios of revascularization to medical therapy (hereafter referred to as the revascularization ratio).

\section{Methods}

\section{Study design and setting}

We conducted an observational cohort study. Our primary data source was the Cardiac Care 
Network of Ontario database. The database receives clinical data from the 18 cardiac centres in the province on all patients who undergo cardiac angiography, PCI or CABG..$^{15,16}$ The database's accuracy has been previously validated by means of retrospective chart review and comparisons with other databases. ${ }^{13,17} \mathrm{We}$ linked the data to those from population-level administrative databases with the use of unique, encoded identifiers (the list of administrative databases is available in Appendix 1, www.cmaj .ca/lookup/suppl/doi:10.1503/cmaj.141372/-/DC1).

The Research Ethics Board at the Sunnybrook Health Sciences Centre, University of Toronto, approved the study design.

\begin{tabular}{|lc|}
\hline $\begin{array}{l}\text { Table 2: Distribution of participating hospitals } \\
\text { by hospital revascularization ratio* }\end{array}$ \\
\hline $\begin{array}{l}\text { Ratio category; } \\
\text { hospital }\end{array}$ & $\begin{array}{c}\text { Revascularization } \\
\text { ratio }\end{array}$ \\
\hline Low ratio & 1.09 \\
\hline $\begin{array}{l}\text { Hôtel-Dieu Grace Hospital } \\
\text { (Windsor) }\end{array}$ & 1.18 \\
\hline $\begin{array}{l}\text { St. Mary's General Hospital } \\
\text { (Kitchener) }\end{array}$ & 1.26 \\
\hline $\begin{array}{l}\text { Brampton Civic Hospital } \\
\text { Southlake Regional Health } \\
\text { Centre (Newmarket) }\end{array}$ & 1.31 \\
\hline $\begin{array}{l}\text { Thunder Bay Regional Health } \\
\text { Sciences Centre }\end{array}$ & 1.34 \\
\hline $\begin{array}{l}\text { University Health Network } \\
\text { (Toronto) }\end{array}$ & 1.41 \\
\hline
\end{tabular}

\begin{tabular}{l} 
Medium ratio \\
\hline $\begin{array}{l}\text { Peterborough Regional } \\
\text { Health Centre }\end{array}$
\end{tabular}

\begin{tabular}{|lc|}
\hline St. Michael's Hospital (Toronto) & 1.45 \\
\hline $\begin{array}{l}\text { Rouge Valley Health System } \\
\text { (Toronto) }\end{array}$ & 1.46 \\
\hline $\begin{array}{l}\text { Sudbury Regional Hospital } \\
\text { (now Health Sciences North) }\end{array}$ & 1.58 \\
\hline London Health Sciences Centre & 1.60 \\
\hline $\begin{array}{l}\text { Trillium Health Centre } \\
\text { (Mississauga) }\end{array}$ & 1.63 \\
\hline
\end{tabular}

\begin{tabular}{|c|c|}
\hline High ratio & \\
\hline Sault Area Hospital & 1.69 \\
\hline Hamilton Health Sciences & 1.76 \\
\hline Toronto East General Hospital & 1.86 \\
\hline $\begin{array}{l}\text { Sunnybrook Health Sciences } \\
\text { Centre (Toronto) }\end{array}$ & 1.96 \\
\hline Kingston General Hospital & 2.13 \\
\hline $\begin{array}{l}\text { University of Ottawa Heart } \\
\text { Institute }\end{array}$ & 2.31 \\
\hline
\end{tabular}

\section{Study population}

We included Ontario residents 20 years of age and over who had stable ischemic heart disease documented by index angiography between Oct. 1, 2008, and Sept. 30, 2011, at any of the 18 cardiac centres. For patients who underwent multiple angiograms within the study period, we included only the first angiogram. To use a conservative definition, we excluded patients with normal coronary arteries, mild coronary artery disease (stenosis $<70 \%$, or $<50 \%$ in the left main artery) or a recent myocardial infarction $(\leq 90 \mathrm{~d}$ before the index angiogram). Patients who underwent PCI or CABG within 90 days after their index angiogram were included in the revascularization group; the remaining patients were included in the medical therapy group. We chose 90 days as the cut-off because it is consistent with current procedural wait times. $^{13,16}$

\section{Determination of revascularization ratios}

We calculated the revascularization ratio for each hospital based on the number of patients who had an index angiogram at that hospital and were subsequently allocated to either revascularization or medical therapy. We then classified the participating hospitals into 3 categories by ratio (high, medium or low) such that there were equal numbers of hospitals in each category.

\section{Outcome measures}

The primary outcome was all-cause mortality, and the secondary outcome was readmission with nonfatal myocardial infarction. Maximum follow-up was until Dec. 31, 2012.

\section{Statistical analysis}

We found that $1.5 \%$ of patients had missing data on details of the procedural physician, and $0.1 \%$ had missing data on whether they had a prior CABG. We excluded these patients from the subsequent regression modelling. We used a 3-level hierarchical logistic regression model to identify drivers of revascularization. To account for clustering of patients by procedural physician and by procedural hospital, we included hospital-specific and physician-specific random effects, with the procedural physician nested within the procedural hospital. We developed 5 models: an unconditional/ null model that contained the physician- and hospital-specific random effects only; a model adjusted for significant patient characteristics; a model adjusted for significant patient and physician characteristics; a model adjusted for significant patient and hospital characteristics; and finally a model adjusted for all variables.

The variance of the distribution of the hospital-specific random effect is a measure of the 
between-hospital variation in the choice of initial treatment strategy. We examined the proportional change in the variance of the random effect between models 1 and 2, 2 and 3, 2 and 4, and 3 and 5, and identified important predictors of revascularization using model 5 .

We compared unadjusted clinical outcomes across the 3 categories of hospital revascularization ratio using Kaplan-Meier curves. We developed adjusted Cox-proportional hazards models using a time-varying covariate for treatment received to address the potential for immortal time bias. The entire cohort was included in the medical therapy category until the time of revascularization (up to a maximum of $90 \mathrm{~d}$ ), at which point they were moved to the PCI or CABG group based on the first revascularization modality received. We used robust "sandwich-type" variance estimators to account for potential homogeneity in outcomes for clusters of patients treated at the same hospital. We adjusted for patient, physician and hospital characteristics and evaluated the association between the revascularization ratio and clinical outcomes. We compared hospitals with high, medium and low revascularization ratios within each treatment strategy by means of an interaction term.

We used SAS version 9.3 (SAS Institute Inc.) for the statistical analyses.

\section{Results}

We identified 39131 patients with stable ischemic heart disease who met our inclusion criteria; 15139 of them received medical therapy, and 23992 underwent revascularization. The baseline characteristics of the patients are reported in Table 1. There were numerous differences between patients in the medical therapy group and those in the revascularization group, with the latter on average being younger and having fewer comorbidities, more diseased vessels and more severe angina symptoms. (The baseline characteristics of patients in the revascularization group by type of procedure are available in Appendix 2, at www.cmaj.ca/lookup/suppl/doi:10.1503/cmaj .141372/-/DC1.)

The mean overall revascularization ratio was 1.58. We observed a twofold variation in the revascularization ratios across the 18 hospitals, from 1.09 to 2.31 (Table 2). In general, patients were relatively similar, with no clinically meaningful differences across the 3 revascularization ratio groups (Appendix 3, available at www.cmaj.ca/lookup /suppl/doi:10.1503/cmaj.141372/-/DC1).

Patient factors significantly associated with an increased likelihood of revascularization instead of medical therapy were history of smoking (odds ratio $[\mathrm{OR}] 1.07,95 \%$ confidence interval $[\mathrm{CI}]$ 1.01-1.12), multivessel disease (2 vessels: OR $1.45,95 \%$ CI $1.34-1.57$; 3 vessels: OR 1.66, 95\% CI 1.47-1.88), high risk findings on noninvasive stress testing (OR 1.27, 95\% CI 1.18-1.36) and more severe symptoms of angina (OR 1.36-2.38 for Canadian Cardiovascular Society [CCS] classes 1-4 relative to CCS class 0) (Table 3). Coronary anatomy was also a strong predictor of revascularization, in particular stenoses in the left main artery (OR 1.51, 95\% CI 1.37-1.67) and the proximal left anterior descending artery (OR 1.69, 95\% CI 1.59-1.79). In contrast, older patients and those with more medical comorbidities and cardiac risk factors were less likely to undergo revascularization. In particular, prior CABG $(\mathrm{OR}$

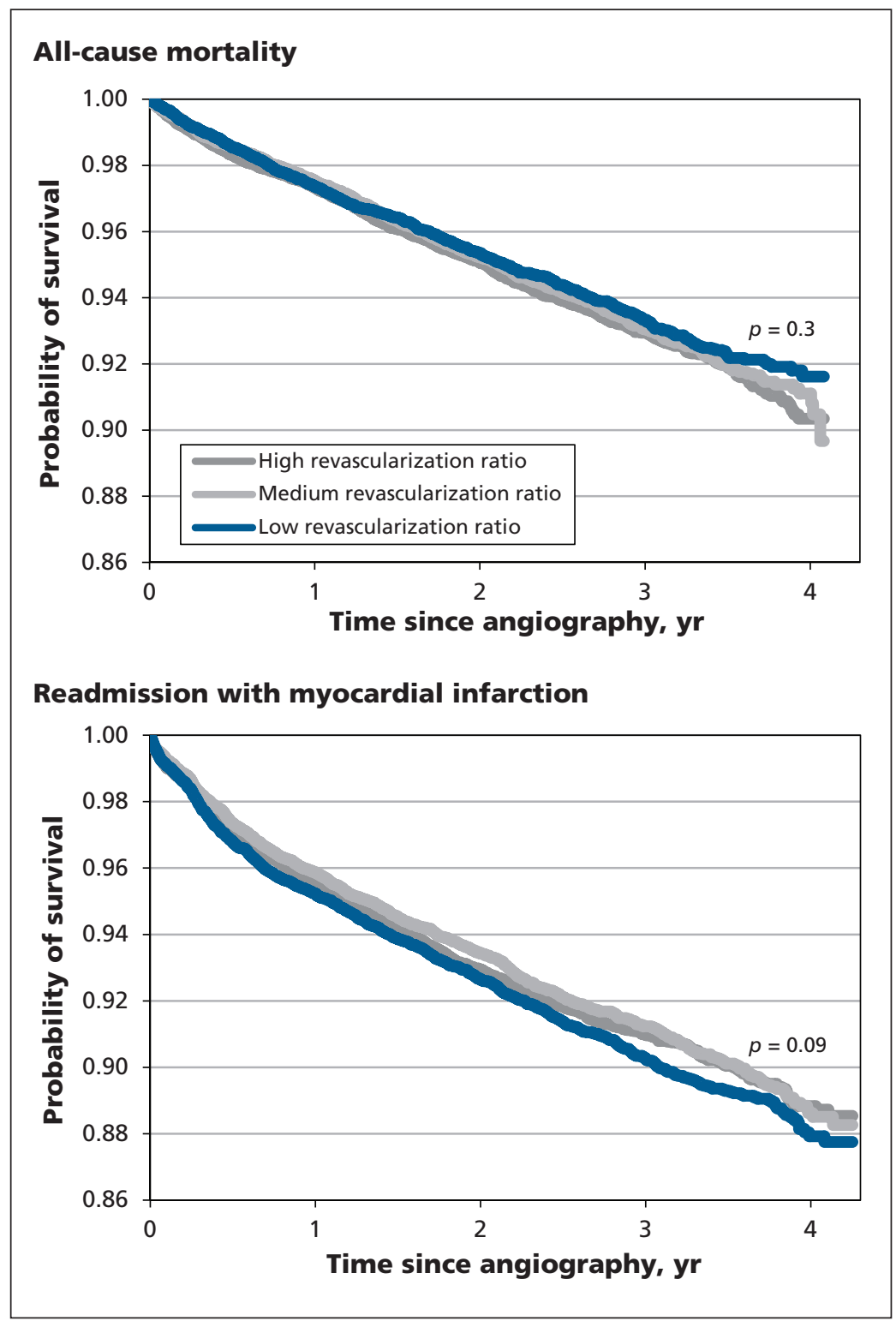

Figure 1: Unadjusted Kaplan-Meier curves for (a) all-cause mortality and (b) readmission with myocardial infarction after index angiography, by category of hospital revascularization ratio. 
$0.19,95 \%$ CI $0.18-0.20)$ and poor left ventricular function (OR 0.50 , 95\% CI $0.45-0.55$ ) were strong predictors of medical therapy (Table 3 ).

Of the physician factors, age was the only significant factor: patients who underwent an angiogram by an older physician were less likely to undergo revascularization (OR $0.97,95 \% \mathrm{CI}$ 0.94-0.99, per year increase) (Table 3). Hospital factors did not significantly predict likelihood of revascularization.

The addition of patient variables reduced the variance of the hospital random effect from 0.0224 in the unconditional model to 0.0073 , for a reduction of $67.4 \%$. Thus, the between-hospital variation in revascularization strategy for a reference patient (one whose patient covariates were all set to zero) was less than the between-hospital variation in crude revascularization ratio. Further addition of physician and hospital variables did not reduce the between-hospital variation in initial treatment strategy (variance estimate 0.0093 after addition of physician variables, 0.0094 after addition of hospital variables, and 0.0116 after addition of physician and hospital variables).

Over a median follow-up of 2.5 years, there was no difference in unadjusted all-cause mortality $(p=0.3)$ or readmission with nonfatal myocardial infarction $(p=0.09)$ between the 3 hospital revascularization ratio categories (Figure 1). In the riskadjusted models, patients treated at a hospital in the high revascularization ratio category were $12 \%$ more likely to die than those treated at a centre in the low ratio category (hazard ratio [HR] 1.12, 95\% CI 1.03-1.21) (Table 4). There was no statis-

Table 3: Factors associated with the likelihood of revascularization instead of medical therapy among patients with stable ischemic heart disease

\begin{tabular}{|c|c|c|c|}
\hline Factor & OR $(95 \% \mathrm{Cl})$ & Factor & OR $(95 \% \mathrm{Cl})$ \\
\hline Patient & & Left ventricular function & \\
\hline Age (per additional $10 \mathrm{yr}$ ) & $0.89(0.87-0.91)$ & $\leq 34 \%$ & $0.50(0.45-0.55)$ \\
\hline Male (v. female) & $1.05(0.99-1.10)$ & $35 \%-49 \%$ & $0.83(0.77-0.89)$ \\
\hline Rural residence (v. urban) & $0.96(0.90-1.03)$ & $\geq 50 \%$ & 1.00 (ref) \\
\hline Income quintile & & Not done & $1.08(1.01-1.14)$ \\
\hline 1 (lowest) & $0.88(0.82-0.95)$ & Exercise ECG risk & \\
\hline 2 & $0.96(0.90-1.04)$ & Low risk & 1.00 (ref) \\
\hline 3 & $0.96(0.89-1.03)$ & High risk & $1.27(1.18-1.36)$ \\
\hline 4 & $0.99(0.92-1.06)$ & Uninterpretable & $1.09(0.97-1.22)$ \\
\hline 5 (highest) & 1.00 (ref) & Not done & $0.94(0.88-1.00)$ \\
\hline Medical comorbidities & & Functional imaging risk & \\
\hline Peripheral vascular disease (v. no disease) & $0.85(0.79-0.92)$ & Low risk & 1.00 (ref) \\
\hline Prior MI (v. no prior MI) & $0.79(0.74-0.83)$ & High risk & $1.07(1.00-1.14)$ \\
\hline COPD (v. no COPD) & $0.84(0.76-0.91)$ & Not done & $1.12(1.05-1.20)$ \\
\hline Charlson comorbidity score & $0.92(0.91-0.94)$ & CCS class & \\
\hline (per additional point) & & 0 & 1.00 (ref) \\
\hline Cardiac risk factors & & 1 & $1.36(1.25-1.47)$ \\
\hline Diabetes (v. no diabetes) & $0.94(0.89-0.99)$ & 2 & $1.81(1.69-1.93)$ \\
\hline Hypertension (v. no hypertension) & $0.89(0.83-0.96)$ & 3 & $2.31(2.14-2.48)$ \\
\hline Hyperlipidemia (v. no hyperlipidemia) & $0.94(0.89-1.00)$ & 4 & $2.38(2.04-2.78)$ \\
\hline History of smoking (v. never smoked) & $1.07(1.01-1.12)$ & Physician $†$ & \\
\hline Cardiac status/testing & & Age, yr (per additional yr) & $0.97(0.94-0.99)$ \\
\hline Native stenosis* (v. nonsignificant stenosis) & & Male (v. female) & $1.29(0.98-1.70)$ \\
\hline Left main coronary artery & $1.51(1.37-1.67)$ & Years since graduation (per additional yr) & $1.02(1.00-1.05)$ \\
\hline $\begin{array}{l}\text { Proxmal left anterior descending } \\
\text { coronary artery }\end{array}$ & $1.69(1.59-1.79)$ & $\begin{array}{l}\text { Total consultations billed per year (per } \\
\text { additional consultation) }\end{array}$ & $1.00(1.00-1.00)$ \\
\hline $\begin{array}{l}\text { Mid or distal left anterior descending } \\
\text { coronary artery }\end{array}$ & $1.18(1.11-1.25)$ & $\begin{array}{l}\text { Total visits billed per yr (per } \\
\text { additional visit) }\end{array}$ & $1.00(1.00-1.00)$ \\
\hline Circumflex artery & $1.03(0.96-1.10)$ & Hospital & \\
\hline Right coronary artery & $1.09(1.02-1.17)$ & Annual catheterization volume (per & $1.00(0.98-1.02)$ \\
\hline Prior CABG (v. no prior CABG) & $0.19(0.18-0.20)$ & additional 1000) & \\
\hline Coronary anatomy & & Hospital type & \\
\hline 1 vessel & 1.00 (ref) & CABG, $\mathrm{PCl}$ and catheterization & 1.00 (ref) \\
\hline 2 vessels & $1.45(1.34-1.57)$ & Catheterization only & $1.05(0.81-1.36)$ \\
\hline 3 vessels & $1.66(1.47-1.88)$ & $\mathrm{PCl}$ and catheterization only & $0.86(0.62-1.20)$ \\
\hline
\end{tabular}


tically significant difference in mortality between the medium and low revascularization ratio categories (HR 1.03, 95\% CI 0.90-1.18). When we compared hospital categories within each treatment strategy, we found that patients who underwent PCI at a centre with a high revascularization ratio had a higher risk of death than those whose PCI was performed at a centre with a low revascularization ratio (HR 1.30, 95\% CI 1.12-1.52). In contrast, mortality did not differ significantly between hospital categories among patients who underwent $\mathrm{CABG}$ or among those who received medical therapy alone (Table 4).

We found no significant differences in the risk of readmission with myocardial infarction between the 3 hospital categories (Table 4). When we compared treatment strategies, we found that patients who underwent PCI were less likely (HR 0.57, 95\% CI 0.39-0.84), and patients who had CABG were more likely (HR 2.04, 95\% CI 1.36-3.08), to be readmitted with myocardial infarction than patients who received medical therapy alone. (The full multivariable Cox models for all-cause mortality and myocardial infarction are available in Appendices 4 and 5, respectively, at www.cmaj.ca /lookup/suppl/doi:10.1503/cmaj.141372/-/DC1.)

\section{Interpretation}

In this study of initial treatment strategies for stable ischemic heart disease after coronary angiography, we found a twofold variation in revascularization ratios across the 18 cardiac centres in Ontario. Our analysis suggests that the variation was attributable primarily to differences in patient factors (67.4\% of the variation). However, one-third of the variation remained unaccounted for. Importantly, the variation we observed between hospitals was associated with a small but statistically significant difference in all-cause mortality, with patients who underwent PCI at a hospital with a high revascularization ratio being at increased risk of death than those whose PCI was performed at a centre with a low revascularization ratio.

Variation in practice patterns has been documented for a wide range of medical procedures. ${ }^{18,19}$ If practice variation is due to factors other than patient characteristics, such as physician and hospital culture, then it may reflect differences in approach based on training, financial incentives and local practice style. ${ }^{20}$ Practice variation is not a negative feature as long as outcomes and costs for treatment are similar once comorbidities are accounted for. However, unwarranted variation may result in differences in clinical outcomes and quality of care that is harmful to patients or in costs that are unnecessarily high if medical procedures are inappropriate. ${ }^{20}$
A better understanding of both the drivers and consequences of variation is needed. We found that patient characteristics were the main driver of between-hospital variation in initial treatment strategy. The specific physician and hospital factors that we evaluated did not have a substantial impact on the variation, which is in contrast to findings from other studies on revascularization practice patterns ${ }^{13}$ and on the degree of optimal medical therapy. ${ }^{21,22}$ Potential explanations for our contrasting results are that patient factors are weighed more heavily in Ontario on the decision of initial treatment strategy for stable ischemic heart disease. Alternatively, given that $32.6 \%$ of the between-hospital variation was not accounted for in our study, practice patterns may have been

Table 4: Association between hospital revascularization ratio and clinical outcomes

\begin{tabular}{|c|c|c|}
\hline Outcome & $\begin{array}{l}\text { Hospital } \\
\text { revascularization ratio }\end{array}$ & $\begin{array}{l}\text { Adjusted HR* } \\
(95 \% \mathrm{Cl})\end{array}$ \\
\hline \multicolumn{3}{|l|}{ All-cause mortality } \\
\hline \multirow[t]{2}{*}{ By revascularization ratio } & High v. low & $1.12(1.03-1.21)$ \\
\hline & Medium v. low & $1.03(0.90-1.18)$ \\
\hline \multicolumn{3}{|l|}{ By treatment } \\
\hline \multicolumn{2}{|l|}{ PCI v. medical therapy } & $0.84(0.57-1.25)$ \\
\hline \multicolumn{2}{|l|}{ CABG v. medical therapy } & $0.96(0.62-1.47)$ \\
\hline \multicolumn{3}{|c|}{ By treatment $\times$ revascularization ratio } \\
\hline \multirow[t]{2}{*}{ CABG } & High v. low & $1.03(0.86-1.23)$ \\
\hline & Medium v. low & $0.84(0.67-1.05)$ \\
\hline \multirow[t]{2}{*}{$\mathrm{PCl}$} & High v. low & $1.30(1.12-1.52)$ \\
\hline & Medium v. low & $1.09(0.94-1.27)$ \\
\hline \multirow[t]{2}{*}{ Medical therapy } & High v. low & $1.06(0.96-1.17)$ \\
\hline & Medium v. low & $1.10(0.92-1.30)$ \\
\hline \multicolumn{3}{|c|}{ Readmission with myocardial infarction } \\
\hline \multirow[t]{2}{*}{ By revascularization ratio } & High v. low & $1.03(0.84-1.26)$ \\
\hline & Medium v. low & $0.90(0.72-1.13)$ \\
\hline \multicolumn{3}{|l|}{ By treatment $\dagger$} \\
\hline \multicolumn{2}{|l|}{$\mathrm{PCl}$ v. medical therapy } & $0.57(0.39-0.84)$ \\
\hline \multicolumn{2}{|l|}{ CABG v. medical therapy } & $2.04(1.36-3.08)$ \\
\hline \multicolumn{3}{|c|}{ By treatment $\times$ revascularization ratio $\neq$} \\
\hline \multirow[t]{2}{*}{ CABG } & High v. low & $0.92(0.72-1.19)$ \\
\hline & Medium v. low & $0.76(0.58-1.00)$ \\
\hline \multirow[t]{2}{*}{$\mathrm{PCl}$} & High v. low & $1.18(0.89-1.56)$ \\
\hline & Medium v. low & $0.93(0.68-1.27)$ \\
\hline \multirow[t]{2}{*}{ Medical therapy } & High v. low & $0.93(0.74-1.18)$ \\
\hline & Medium v. low & $0.93(0.73-1.19)$ \\
\hline \multicolumn{3}{|c|}{$\begin{array}{l}\text { Note: } \mathrm{CABG}=\text { coronary artery bypass grafting, } \mathrm{Cl}=\text { confidence interval, } \mathrm{HR}=\text { hazard ratio, } \\
\mathrm{PCl}=\text { percutaneous coronary intervention. } \\
{ }^{*} \text { Adjusted for all patient, physician and hospital factors. } \\
\text { †Time-varying covariate for treatment received. } \\
\text { ‡Analyzed by an interaction model. }\end{array}$} \\
\hline
\end{tabular}


influenced by components of hospital and physician culture that were not captured by the administrative data used in our analyses. Future research should explore other aspects of physician and hospital culture.

Because our study population had stable ischemic heart disease, overall mortality was low. Regardless, we observed small but statistically significant differences in mortality between hospitals with high and low revascularization ratios. It is important to note that our primary focus was not on the comparison of PCI or CABG with medical therapy. Although we did not find any differences in mortality, we found a statistically significant difference in readmission for myocardial infarction that requires further study. Rather, our primary focus was on the outcomes of all patients (having accounted for the actual treatment received) at high versus medium versus low revascularization ratio hospitals. We can only speculate as to the reason for the differences in outcomes we observed. One possible reason for the increased mortality at hospitals with a high revascularization ratio may be because these hospitals treat sicker patients; therefore, higher mortality was due to residual confounding from incomplete adjustment. We cannot discount this possibility, but we have 2 counterarguments. First, hospitals with a high revascularization ratio likely perform both higher risk PCI and CABG; as such, the lack of a significant between-hospital difference in mortality in the CABG group suggests against residual confounding as the primary driver. Second, the baseline characteristics of patients were relatively similar across the 3 hospital categories; therefore, the quality of care may have been lower at hospitals with a high revascularization ratio. This may seem contradictory to previous work that showed a strong association between procedural volume and quality of care..$^{23-25}$

We did not compare centres according to their procedure volumes. Instead, we compared outcomes based on the threshold to revascularize a reference patient. Our results suggest that treatment at hospitals with a high revascularization ratio, which have a lower threshold for revascularization in a reference patient, is associated with increased mortality. We hypothesize that a lower threshold for revascularization in stable ischemic heart disease may put patients at risk of an invasive procedure without a substantial benefit. In addition, a focus on revascularization may divert attention away from aggressive medical therapy and thus prevent optimal medical therapy to be realized. We postulate that the reason our findings were isolated to PCI patients is because of the less discretionary nature of $\mathrm{CABG},{ }^{26}$ which would reduce the likelihood of inappropriate procedures.

\section{Limitations}

Several limitations to our study merit discussion. First, we limited our outcome measures to death and readmission with myocardial infarction. Because revascularization is primarily for symptom relief, the between-hospital variation we observed may have had an impact on quality of life or productivity, which we were unable to assess. Second, we were limited to evaluating physician and hospital factors that were captured in the databases available. Third, we conducted a complete case analysis, excluding $2 \%$ of patients in the cohort who had missing data. We do not anticipate that excluding these few patients from our analyses would qualitatively affect our conclusions. Finally, given the observational nature of the study, our findings should be considered hypothesis generating, not conclusive.

\section{Conclusion}

We identified important factors associated with the choice of initial treatment strategy for stable ischemic heart disease. Most of the variation in revascularization ratios across the 18 cardiac centres was explained by patient factors. Nonetheless, the variation was associated with potentially important differences in clinical outcomes.

\section{References}

1. Cardiovascular diseases (CVDs). Geneva: World Health Organization. Available: www.who.int/mediacentre/factsheets/fs317/en/ (updated January 2015; accessed 2015 Apr. 24).

2. Wijeysundera HC, Machado M, Farahati F, et al. Association of temporal trends in risk factors and treatment uptake with coronary heart disease mortality, 1994-2005. JAMA 2010;303:1841-7.

3. Cannon CP, Waheed S. Evaluating medical, percutaneous coronary intervention, and coronary artery bypass surgery options for chronic angina: an update of the revised guidelines. Rev Cardiovasc Med 2009;10(Suppl 1):S21-9.

4. Opie LH, Commerford PJ, Gersh BJ. Controversies in stable coronary artery disease. Lancet 2006;367:69-78.

5. Simoons ML, Windecker S. Controversies in cardiovascular medicine: Chronic stable coronary artery disease: drugs vs. revascularization. Eur Heart J 2010;31:530-41.

6. Boden WE, O'Rourke RA, Teo KK, et al. Impact of optimal medical therapy with or without percutaneous coronary intervention on long-term cardiovascular end points in patients with stable coronary artery disease (from the COURAGE Trial). Am J Cardiol 2009;104:1-4.

7. Breeman A, Hordijk-Trion M, Lenzen M, et al. Treatment decisions in stable coronary artery disease: insights from the Euro Heart Survey on Coronary Revascularization. J Thorac Cardiovasc Surg 2006;132:1001-9.

8. Shaw LJ, Berman DS, Maron DJ, et al. Optimal medical therapy with or without percutaneous coronary intervention to reduce ischemic burden: Results from the Clinical Outcomes Utilizing Revascularization and Aggressive Drug Evaluation (COURAGE) trial nuclear substudy. Circulation 2008;117:1283-91.

9. Patel MR, Dehmer GJ, Hirshfeld JW, et al. ACCF/SCAI/STS/ AATS/AHA/ASNC 2009 appropriateness criteria for coronary revascularization: a report of the American College of Cardiology Foundation Appropriateness Criteria Task Force, Society for Cardiovascular Angiography and Interventions, Society of Thoracic Surgeons, American Association for Thoracic Surgery, American Heart Association, and the American Society of Nuclear Cardiology. Circulation 2009;119:1330-52.

10. Chan PS, Patel MR, Klein LW, et al. Appropriateness of percutaneous coronary intervention. JAMA 2011;306:53-61.

11. Ko DT, Tu JV, Austin PC, et al. Prevalence and extent of obstructive coronary artery disease among patients undergoing elective coronary catheterization in New York State and Ontario. 
JAMA 2013;310:163-9.

12. Ko DT, Tu JV, Samadashvili Z, et al. Temporal trends in the use of percutaneous coronary intervention and coronary artery bypass surgery in New York State and Ontario. Circulation 2010;121 2635-44.

13. Tu JV, Ko DT, Guo H, et al. Determinants of variations in coronary revascularization practices. CMAJ 2012;184:179-86.

14. Hannan EL, Wu C, Walford G, et al. Drug-eluting stents vs. coronary-artery bypass grafting in multivessel coronary disease. N Engl J Med 2008;358:331-41.

15. About the Cardiac Care Network of Ontario. Toronto: Cardiac Care Network; 2009. Available: www.ccn.on.ca/ccn_public/ FormsAboutCCN/about.aspx (accessed 2015 May 1).

16. Annual report 2001-2012. Toronto: Cardiac Care Network; 2012. Available: www.ccn.on.ca/ccn_public/uploadfiles/files/ CCN_Annual_Report 2012.pdf (accessed 2015 May 1).

17. Gurevich Y, McFarlane A, Morris K, et al. Estimating the number of coronary artery bypass graft and percutaneous coronary intervention procedures in Canada: a comparison of cardiac registry and Canadian Institute for Health Information data sources. Can J Cardiol 2010;26:e249-53.

18. Wennberg DE, Birkmeyer JD, Bronner KK, et al. The quality of medical care in the United States: a report on the Medicare program. Chicago: American Heart Association Press; 1999. Available: www.dartmouthatlas.org/downloads/atlases/99Atlas.pdf (accessed 2015 Apr. 24)

19. Lucas FL, DeLorenzo MA, Siewers AE, et al. Temporal trends in the utilization of diagnostic testing and treatments for cardiovascular disease in the United States, 1993-2001. Circulation 2006;113:374-9.

20. Hlatky MA, DeMaria AN. Does practice variation matter? J Am Coll Cardiol 2013;62:447-8.

21. Cordero A, Bertomeu-Martinez V, Mazon P. Differences in medical treatment of chronic coronary heart disease patients according to medical specialities. Cardiovasc Ther 2009;27:173-80.

22. Cram P, Rosenthal GE, Vaughan-Sarrazin MS. Cardiac revascularization in specialty and general hospitals. N Engl J Med 2005; 352:1454-62.

23. Dudley RA, Johansen KL, Brand R, et al. Selective referral to high-volume hospitals: estimating potentially avoidable deaths. JAMA 2000;283:1159-66.

24. Halm EA, Lee C, Chassin MR. Is volume related to outcome in health care? A systematic review and methodologic critique of the literature. Ann Intern Med 2002;137:511-20.

25. Birkmeyer JD, Dimick JB, Staiger DO. Operative mortality and procedure volume as predictors of subsequent hospital performance. Ann Surg 2006;243:411-7.
26. Hux JE, Naylor CD. Are the marginal returns of coronary artery surgery smaller in high-rate areas? The Steering Committee of the Provincial Adult Cardiac Care Network of Ontario. Lancet 1996;348:1202-7.

Affiliations: Schulich Heart Centre (Bennell, Wijeysundera), Division of Cardiology, Sunnybrook Health Sciences Centre, University of Toronto; the Institute of Health Policy, Management and Evaluation (Austin, Wijeysundera), University of Toronto; the Institute for Clinical Evaluative Sciences (Qiu, Austin, Wijeysundera); the Cardiac Care Network of Ontario (Kingsbury), Toronto, Ont.

Contributors: Harindra Wijeysundera was responsible for the study concept and design. All of the authors contributed to the analysis and interpretation of the data. Maria Bennell drafted the manuscript, and all of the authors revised it for important intellectual content. All of the authors approved the final version to be published and agreed to be guarantors of the work.

Funding: The funding sources for this study are the Canadian Institutes of Health Research (grant no. MOP-123418); the Schulich Heart Centre, Sunnybrook Health Sciences Centre; and the Sunnybrook Research Institute, Sunnybrook Health Sciences Centre. The clinical registry data used in the study were obtained from the Cardiac Care Network of Ontario and its member hospitals. The network is funded by the Ontario Ministry of Health and Long-Term Care; it serves as an advisory body to the ministry and is dedicated to improving the quality, efficiency, access and equity of adult cardiovascular services in Ontario. The study was also supported by the Institute for Clinical Evaluative Sciences, which is funded by an annual grant from the Ontario Ministry of Health and LongTerm Care. The funding organizations did not have a role in the design and conduct of the study; the collection, management, analysis or interpretation of the data; or the preparation, review or approval of the manuscript. No endorsement by the Institute for Clinical Evaluative Sciences or the Ontario Ministry of Health and Long-Term Care is intended or should be inferred.

Harindra Wijeysundera is supported by a Distinguished Clinical Scientist Award from the Heart and Stroke Foundation of Canada. Peter Austin is supported in part by a Career Investigator Award from the Heart and Stroke Foundation. 